\title{
PROPOSTA DE INCLUSÃO DE CARGA HORÁRIA SEMIPRESENCIAL EM CURSOS SUPERIORES PRESENCIAIS
}

\author{
Emílio Rodrigues Junior*; Fabricio Juliano Fernandes**
}

Recebido: 06 jun. $2012 \quad$ Aprovado: 06 dez. 2012

* Faculdade de Ciências Administrativas de Cuiabá. Cuiabá, MT, Brasil. Contato: junior-emilio@bol.com.br

** Faculdade de Ciências Administrativas de Cuiabá. Cuiabá, MT, Brasl. Contato: fajufer10@yahoo.com.br

Resumo: Com as tecnologias digitais e educacionais, a aplicação de conceitos, teorias e metodologias mais interativas e dinâmicas estão sendo utilizadas na Educação a Distância (EaD), mudando o foco do processo de ensinar/aprender. O presente texto tem o objetivo de analisar a evolução da educação a distância e a possibilidade de inclusão da modalidade semipresencial em cursos superiores de graduação já reconhecidos pelo Ministério da Educação. A implantação da semipresencialidade, devidamente regulamentada pela portaria 4.059, deve ser discutida em cada Instituição de Ensino, uma vez que as realidades são distintas e as necessidades de formação dos professores que irão atuar nessa modalidade não são as mesmas. O presente estudo surge na seqüência de diversas preocupações e tem como problema de pesquisa: é possível e viável a implantação de $20 \%$ da carga horária a distancia? Com as novas tecnologias, as Instituições podem adaptar os projetos pedagógicos dos cursos prevendo a inclusão da semipresencialidade em cursos já reconhecidos. Essa modalidade pode favorecer o desenvolvimento da aprendizagem autônoma nos estudantes. Evidentemente que o professor tem papel decisivo na efetivação do processo e precisará estar preparado para esta nova situação de aprendizagem, sob pena de criar resistências e comprometer o espírito do ensino presencial. Não se trata de uma facilidade e sim de um acompanhamento do professor nas execuções das atividades complementares de estudo. Isso posto, não se pode prescindir de investigar a realidade em que estes sujeitos estão inseridos, especialmente sua prática pedagógica, formação e experiências e a relação que mantêm dentro e fora da escola, uma vez que esses elementos poderão ser determinantes na medida em que os objetivos e expectativas pela incorporação das novas tecnologias podem vir a modificar a ação docente. As novas tecnologias podem ser aliadas e melhor utilizadas nas interações com os alunos, sendo útil o seu aprendizado. A inclusão do ensino semipresencial nos cursos de graduação, portanto, é validada e benéfica quando realizada de forma coerente, com anuência dos envolvidos e com fins pedagógicos e não econômicos.

Palavras-chave: Educação a distancia. Ensino semipresencial. Professores. Ensino e aprendizagem. Tecnologias de informação.

\section{PROPOSAL FOR INCLUSION OF PARTIALLY NON-CLASSROOM BASED TRAINING IN HIGHER EDUCATION COURSES}

Abstract: With digital technologies and educational application of concepts, theories and more interactive and dynamic methodologies are being utilized in Distance Education (EaD), shifting the focus of the process of teaching / learning. This paper aims to analyze the evolution of distance education and the possibility of inclusion of a blended mode in higher education programs already recognized by the Ministry of Education. The implementation of semiclassroom, properly regulated by Ordinance 4.059 , should be discussed in each educational institution, since the realities are different and the training needs of teachers who will work in this mode are not the same. This study comes in the wake of several concerns and has this research problem: is it possible and feasible to allocate $20 \%$ of the teaching load to distance education? With new technologies, institutions can adapt the design of educational courses providing for the inclusion of semiclassroom courses al- 
ready recognized. This modality may favor the development of autonomous learning in students. Of course, the teacher plays a decisive role in the effectiveness of the process and needs to be prepared for this new learning situation, running the risk of creating resistance and undermining the spirit of teaching. This is not meant as a facilitator but the monitoring by the teacher of complementary activities. That said, one can not ignore to investigate reality in which these subjects are inserted, especially their teaching, training and experience and their relationship inside and outside the school, since these elements may impact the extent that the objectives and expectations for the incorporation of new technologies may modify the teaching. New technologies can be combined and better used in the interactions with students, and knowing how to apply them can be very useful. The inclusion of blended learning in undergraduate programs, therefore, is validated and beneficial when performed consistently, and carried out with the consent of those involved in educational, non economic purposes.

Key words: Distance education. Teaching semi classroom. Teachers, Teaching and Learning. Information technology.

\section{INTRODUÇÃO}

A educação sofreu ao longo dos séculos significativas transformações. Da antiga paidéia (paideia) aos modernos ambientes virtuais de ensino e pesquisa muitos paradigmas se sucederam.

O século XXI, mais especificamente, está marcado pelo grande avanço da tecnologia, principalmente no que diz respeito à informática e comunicação. A sociedade contemporânea está cercada dos mais diferentes recursos tecnológicos como aparelho celular, caixas eletrônicos nos bancos, internet, entre outros. Os avanços surgem com uma velocidade nunca vista em outros tempos. $\mathrm{O}$ acesso a inúmeras informações e das mais diversas fontes podem provocar, por vezes, a sensação de que o sujeito está desinformado, já que nem sempre é possível acompanhar esse ritmo tão acelerado de veiculação de conteúdos (KENSKI, 2003).

O neologismo telemática surge, neste contexto, para tentar dar conta do complexo universo que abarca e cruza a informática com a telecomunicação, revolucionando o armazenamento, processamento e transmissão de conteúdos e informações (MERCADO, 1999).

Com a consolidação das tecnologias educacionais, estão sendo aplicadas, na Educação a Distancia, teorias e metodologias mais interativas e dinâmicas, mudando o aspecto de ensinar e de aprender. Tais mudanças ocorrem em cursos totalmente virtuais, mas também em cursos semipresenciais. Nos dois casos o aluno é o centro das atenções, realizando a autoaprendizagem.

Essa inovação surge a partir da publicação da portaria do MEC 2.253/2001, reformulada pela portaria MEC 4.059/04 (BRASIL, 2004), que sugere a oferta de disciplinas integrantes do currículo do ensino superior que utilizem modalidade semipresencial. 
Este estudo surge a partir do reconhecimento de que o potencial que as tecnologias de informação e comunicação oferecem, constituem ferramentas importantes na educação, inclusive no ensino presencial.

A utilização dessas tecnologias já deixou de ser um desafio para muitos, porém, faz-se necessário que as Instituições de Ensino Superior - IES - além dos cuidados em cumprir as determinações legais para essa implantação, trabalhem na capacitação dos docentes e busquem meios de garantir a qualidade na oferta do ensino. No entanto, utilizar estas ferramentas com comprometimento e planejamento adequados são fatores que ainda devem ser amplamente discutidos.

A informática passou a ser um instrumento de trabalho e uma fonte metodológica para ensino. A sociedade vive visualmente dirigida, onde se torna notório que as tecnologias de informação tem influenciado no processo de ensino e aprendizagem. A sociedade contemporânea vive conectada à informatização, o que acarreta uma mudança considerável na velocidade da propagação da informação, da mesma forma que colabora para a criação de ambientes virtuais e de um novo espaço de comunicação e construção do conhecimento. A antiga àgora (algora) como espaço físico e público de debates e discussão tem, nos ambientes virtuais, seu novo formato. Essa possibilidade permite o debate acerca da viabilidade e qualidade do ensino semipresencial em cursos de graduação presencial.

O desenvolvimento de um modelo de ensino semipresencial para cursos de graduação presencial não significa perda da qualidade, uma vez que esses elementos poderão ser determinantes na medida em que os objetivos e expectativas pela incorporação das novas tecnologias contribuem para implementação de um novo modelo de Educação Superior.

A educação a distância rompe paradigmas de ensino e torna-se um importante instrumento utilizado pelas instituições de ensino superior, introduzindo nos cursos de graduação já reconhecidos, a modalidade semipresencial para até $20 \%$ da carga horária da disciplina ou do curso.

Tal prática força vários debates. Um deles é acerca do papel do professor nesta modalidade de ensino. Nem todos os docentes sentem-se preparados para atuar na educação a distância, pois a educação por meios tecnológicos torna o ensino mais complexo. O processo de selecionar, organizar e transmitir o conhecimento no ensino presencial é de um modo, na educação a distância é de outro (BELLONI, 2009). O segundo debate é em torno da autonomia do acadêmico. $\mathrm{O}$ estudante também precisará se adaptar. A carga horária de $20 \%$ exigirá do aluno disciplina e comprometimento. Ele passa a ser responsável pela própria aprendizagem. 


\section{HISTÓRICO DA EAD NO BRASIL}

A Educação a Distância no Brasil surge com a disseminação dos meios de comunicação. Portanto, não é tão recente como se poderia pensar. A novidade é a educação a distância com as ferramentas modernas, engendrada de um modo sistemático e abrangente, regulada, supervisionada e avaliada pelo Ministério da Educação.

O primeiro formato do ensino a distância foi aquele realizado por meio de correspondência. $\mathrm{O}$ interessado recebia o material em casa, estudava autonomamente, realizava as atividades e ao fim do processo era certificado. Os Institutos Monitor (1939) e Universal Brasileiro (1941) foram os pioneiros (CARLINI; TARCIA, 2010). Após esse período embrionário a educação a distância passou a ser trabalhada por meio de outros veículos de informação. A radiodifusão, através do reconhecido trabalho de Edgar Roquette-Pinto no Rio de Janeiro, surgiu com caráter instrutivo e foi aos poucos atuando na educação a distância. As tele-aulas, posteriormente, servindo-se dos aparelhos televisivos ganharam espaço e contribuíram para sedimentar a aplicação da tecnologia à educação.

Em termos mais específicos e a título de informação vale ressaltar que no inicio da década de 70 foi criado o sistema o Programa Nacional de Teleducação (Prontel) na estrutura do Ministério da Educação e Cultura, que coordenava a Teleducação no Brasil. Anos depois este órgão foi substituído pela secretaria de educação tecnológica (SEAT), hoje extinta. Ainda em 1972 foi criada a Fundação Centro Brasileiro de Televisão Educativa, que em 1981 passou a chamar-se FUNTEVE fortalecendo sobremaneira o Sistema Nacional de Radiodifusão Educativa (SINREAD). O objetivo era veicular programas educativos por meio de acordos e parcerias com rádios e canais de televisão (PRETI, 2011).

Note-se que na década de 70 o MEC realizou com a Empresa Brasileira de Telecomunicações (Embratel) um trabalho integrado e contínuo no sentido de atender "com a devida urgência às necessidades educacionais de todo o território brasileiro com a utilização dos valiosos instrumentos postos à disposição dos educadores pelo avanço tecnológico das telecomunicações". (BRASIL, s.d.). Portanto é evidente já nas décadas de 60, 70 e 80 o estímulo do emprego na educação dos "valiosos" meios trazidos pela tecnologia da comunicação.

Após esse período um divisor de águas revolucionou os processos e as relações humanas. Na década de 90 a informática ganha campo e inova tudo ao 
seu redor. Hoje utiliza-se a informática praticamente em todos os processos, fazendo com que a informação chegue com mais rapidez, independente da localização geográfica (SARAIVA, 1996). O homem tem aprendido com ela a "colonizar o tempo e o espaço", sobretudo com as tecnologias de mobilidade. E colonizar o tempo e o espaço significa gerar e reproduzir conhecimentos e informações rapidamente (SACCO; SCHLEMMER; BARBOSA).

Em relação a EaD, a utilização de novas tecnologias, de forma educativa, a partir dos anos 90, propiciou a ampliação e a diversificação dos programas, permitindo a interação quase presencial entre professores e alunos. Nesse sentido de proximidade entre o mediador e o educando o professor Romero Tori intitula a primeira parte de seu livro "Educação sem Distancia" de um modo muito sugestivo: a distância que aproxima (TORI, 2010).

Com o reconhecimento da importância do ensino a distância em um país com dimensões geográficas do Brasil, foi criada em 1992 a Coordenadoria Nacional de Educação a Distância e, em 1995, a Secretaria de Educação à Distância.

As transformações da educação são hoje amplamente sentidas, dentre as quais está a inclusão da EaD. Trata-se de uma nova nomenclatura que traz em seu conceito uma nova perspectiva no processo de ensino, utilizando-se dos modernos avanços das tecnologias.

Conforme Oreste Preti nunca a educação brasileira foi tão adjetivada: educação para o transito, educação ambiental, educação sexual, educação para a vida, educação do campo, educação para o trabalho, educação a distância, entre outros. O perigo é o desvio do foco. Ao deslocar a atenção para o adjetivo o substantivo fica em segundo plano. Assim embora o ensino a distância seja uma modalidade distinta do presencial é importante a consciência que se trata de educação. Uma educação que se serve das diferentes tecnologias para atingir seus objetivos.

Para Moram (2009), a educação ocorre em três formatos, sendo elas presencial; semipresencial e a distancia, qualquer que seja o nível. Por tradição, na modalidade presencial os professores e alunos são alocados em uma sala de aula, no mesmo espaço físico e sempre no mesmo horário. Já o semipresencial é aquela modalidade em que as aulas são divididas em uma parte presencial sendo a outra parte a distância. Nos momentos das aulas à distância, a interação ocorre por meio de tecnologias. Já a educação a distância em si, como o próprio nome sugere, é aquela em que professores e alunos estão separados fisicamente, embora nem sempre estejam distantes, podendo acontecer ou não em horários diferenciados um dos outros. 


\section{LEGISLAÇÃO SOBRE A EAD}

Como visto a educação a distância nasceu ligada aos veículos de comunicação. Ela foi, paulatinamente, amadurecendo e adquirindo importância no contexto social e geográfico do Brasil. Hoje a educação a distancia é reconhecida como processo válido de ensino e de inclusão social. A sua maioridade deu-se com a Lei de Diretrizes e Bases da Educação (LDB) de 1996. O artigo 80 é claro ao dizer da participação do poder público no estímulo ao desenvolvimento de programas de ensino a distância. E o incentivo do Estado deverá ser em todos os níveis e modalidades de ensino (BRASIL.MEC, 1996).

$\mathrm{O}$ artigo 80 da LDB foi posteriormente regulamentado pelo decreto 5.622 de 19 de dezembro de 2005. No primeiro artigo deste decreto aparece aquilo que caracteriza a educação a distância: modalidade de ensino onde a mediação didático-pedagógica dá-se por meio de tecnologias de informação e comunicação, sublinhando que estudantes e professores estão em lugares ou tempos diversos (BRASIL.MEC, 2004).

O referencial de ensino centrado na reunião de pessoas no mesmo horário e espaço físico é rompido. O decreto 5.622 é explicito: há na educação a distância, uma separação entre os atores do processo de ensino. Separação geográfica e espacial (CARLINI; TARCIA, 2010).

Outro aspecto diz respeito a possibilidade de separação temporal. Não é preciso, necessariamente, a presença do tutor em todas as atividades desenvolvidas. O aluno pode organizar o tempo de estudo a seu modo. Tal flexibilidade pode ser positiva se aliada ao principio da autonomia e organização do estudante. Ele, ao escolher os horários de estudo, sentir-se-á responsável por si e pela sua formação e, ao mesmo tempo, levará em consideração sua predisposição física e emocional para o aprendizado naquele momento.

Ainda no aspecto legal, é importante destacar que as Instituições de Ensino Superior, podem ofertar, em cursos presenciais devidamente reconhecidos pelo Ministério da Educação, disciplinas ou parte da carga horária das disciplinas, na modalidade semipresencial. Em conformidade com a Portaria 4.059 , de 10 de dezembro de 2004, tal prática é possível mesmo em instituições que ainda não tenham sido credenciadas para a modalidade de EaD. Assim as Instituições de Ensino Superior estão autorizadas a oferecer até $20 \%$ da carga horária de uma disciplina ou da carga horária total de um curso na modalidade semipresencial (BRASIL.MEC, 2004).

As instituições de Ensino Superior por meio da Resolução $\mathrm{N}^{\circ}$ 2, de 18 de junho de 2007, dispõem sobre carga horária mínima e procedimentos rela- 
tivos à integralização e duração dos cursos de graduação, bacharelados, na modalidade presencial. Por exemplo, para carga horária mínima de curso de 2.400 horas, com $20 \%$ de carga-horária semipresencial terá 480 horas, para carga-horária mínima de 2.700 horas, 540 horas corresponderá aos $20 \%$ da carga-horária semipresencial (BRASIL.MEC, 2007a).

Considerando o disposto na legislação e a possibilidade de oferecer disciplinas de forma semipresencial, faz-se necessário projetar um modelo pedagógico de EaD que possibilite o alcance pleno dos objetivos educacionais da mesma forma que no oferecimento de disciplinas presenciais. Nesse sentido, o planejamento pedagógico/tecnológico precisa ser pensado e implementado de forma sistemática e devem se sobrepor aos interesses econômicos das Instituições.

\subsection{Modalidade Semipresencial no Ensino Superior}

Apesar de se tratar de uma modalidade antiga, a EaD modernizou-se com a sucessão de gerações de tecnologias, com a pesquisa e a implementação de metodologias e práticas pedagógicas. As práticas sociais, atividades culturais, a convivência, as relações comerciais, as relações humanas e a educação são cada vez mais orientadas pelas tecnologias de informação e comunicação (MORAM, 2002).

O Governo Brasileiro, atento às modernas tendências didático-pedagógicas mundiais, que objetivam implementar novas modalidades educativas que incluem métodos e práticas de ensino-aprendizagem que incorporem o uso integrado de tecnologias de informação e comunicação, tem estimulado as Instituições de Ensino Superior a incorporar disciplinas que usem, no todo ou em parte, metodologias semipresenciais.

As orientações para esta oferta estão descritas na portaria $\mathrm{n}^{\circ} 4.059$, de 10 de dezembro de 2004 (DOU de 13/12/2004, seção 1, p. 34) como mencionado anteriormente.

Diversas Instituições de Ensino Superior, na perspectiva de atender seus alunos nas mais diferentes modalidades de ensino, capacitando-os para este novo mundo educacional vem apresentando disciplinas mediadas por tecnologia, garantindo assim o acesso dos seus alunos ao que há de mais atual no cenário educacional, e possibilitando a adoção um perfil múltiplo de aprendizado (MORAM, 2002).

No caso específico da adoção de $20 \%$ da carga horária total de um curso ou de uma disciplina na modalidade semipresencial significa, obviamente, que 
ela possui características especificas: o emprego da tecnologia de educação a distância; a ação educativa poderá se dar em tempos diferentes; os espaços físicos são distintos, autonomia do estudante. Portanto é possível notar que o que caracteriza a semipresencialidade, inclusive conforme a portaria 4.059 são: a autoaprendizagem, a mediação de recursos didáticos organizados em suportes de informação, o uso de tecnologia de comunicação remota (BRASIL.MEC, 2004).

Com isso evidencia-se o fato de haver uma interrelação entre a educação a distância e a modalidade semipresencial de ensino.

A modalidade semipresencial configura-se a partir do momento em se define que $80 \%$ da carga horária será cumprida de modo presencial, alunos e professores reunidos em ambiente comum, e 20\% "a distância", alunos e professores em espaços distintos e não necessariamente conectados ao mesmo tempo. Note-se que o processo de ensino e aprendizagem e os conteúdos essenciais são trabalhados no modo presencial (80\%). Os conteúdos complementares, extensionistas, ilustrativos é que são trabalhados através dos recursos e tecnologias empregadas na educação (20\%). Isso posto significa que no ensino semipresencial o docente estará no mesmo espaço físico que o aluno para a orientação educativa que irá gerar a aprendizagem. Os recursos tecnológicos criarão os ambientes virtuais apenas para as atividades complementares de estudo. $\mathrm{O}$ centro do processo de ensino e aprendizagem, na modalidade semipresencial, continua sendo a escola, a sala de aula (CARLINI; TARCIA, 2010).

Tal prática, embora devidamente normatizada pelo MEC, não está presente em todas as Instituições de Ensino Superior. É possível que ainda haja resistências por parte de alunos e professores.

O ensino semipresencial se não dirigido e normatizado adequadamente pela Instituição pode gerar confusão na comunidade acadêmica.

Alguns docentes, equivocadamente, temem a tecnologia, julgando que esta poderá substituí-los em sala de aula. Perdem com isso a oportunidade de sair da zona de conforto e assumir os desafios de um novo modelo de educação (CARLINI; TARCIA, 2010).

\section{A INCLUSÃO DA SEMIPRESENCIALIDADE EM CURSOS PRESENCIAIS ${ }^{1}$.}

Antes de mais nada tenha-se presente que a inclusão da semipresencialidade em cursos de graduação é possível apenas para os cursos já reconhe-

1 As professoras Rita Maria Lino Tarcia e Ana Lucia Tinoco Cabral discutem amplamente a implantação de $20 \%$ a distância nas Instituições de Ensino enfatizando aspectos legais e contextuais, o processo efetivo de implantação e os protótipos pedagógicos para a implantação da semipresencialidade. 
cidos. Para efetivar essa inclusão não é necessário que a Instituição esteja credenciada para a modalidade EaD. Ainda conforme a portaria 4.059/04 esta inclusão deve estar contemplada no projeto pedagógico do curso. Como existe a possibilidade do limite de $20 \%$ da carga horária ser aplicada integralmente a uma única disciplina é preciso considerar que as avaliações, nesse caso, devem ser feitas na Instituição, portanto, de modo presencial.

Feitas tais considerações importa agora tratar do processo de inclusão da semipresencialidade em cursos já reconhecidos.

Não é tarefa fácil. A Portaria que regula essa modalidade é do final de 2004. Pouco mais de sete anos até a presente data. É possível que haja entre os docentes aqueles que possuem um conhecimento apenas superficial desta modalidade e da possibilidade de ser implantada no ensino convencional.

Nesse contexto a inclusão da educação semipresencial pode gerar resistências. Essa modalidade pode expor as fragilidades do docente que, num ato de defesa, negará sua eficácia. Pode haver, dado essa realidade, focos de resistência entre os professores.

A sugestão é que a implantação seja gradativa, considerando sempre a necessidade do planejamento das ações. E ao planejar a inclusão da semipresencialidade deve-se pensar na capacitação dos professores. Criar na Instituição e, sobretudo, nos docentes uma cultura do emprego das tecnologias nos processos educativos. Isso pode significar maior segurança na efetivação do ensino semipresencial nos cursos de graduação.

Conforme enfatizam Carlini e Tarcia (2010) a preparação paulatina desse processo poderá ser feita por meio de encontros para troca de experiências já que "os professores não tem uma vivência construída na situação a distância semelhante à que já possuem no presencial".

Após esta fase de sensibilização, esclarecimento de dúvidas, troca de experiências, de uma capacitação inicial para que o professor sinta-se preparado para esse desafio é fundamental destacar os parâmetros para efetivação dessa modalidade. A efetivação passará necessariamente pela definição se o limite de $20 \%$ será dividido entre todas as disciplinas, ou será empregado em um grupo de disciplinas afins ou se será integralmente aplicada a uma disciplina. Além disso, é importante tratar da produção do material a ser disponibilizado no ambiente virtual de estudo e a definição de um protótipo para dar regularidade de elementos em cada ação do ensino a distância (CARLINI; TARCIA, 2010).

A inclusão da semipresencialidade, se bem palnejada, pode representar benefícios para os envolvidos no processo. 
Os professores tem a oportunidade de uma reciclagem em termos de recursos tecnológicos aplicados à educação. O exercício do magistério pode ganhar em inovação e dinamicidade.

O aluno é estimulado quanto ao valor da autodisciplina. Ele precisará se auto formar, desenvolvendo sua autonomia enquanto agente no processo de ensino aprendizagem.

A Instituição, caso não predomine o interesse econômico sobre o pedagógico, também se beneficiará da semipresencialidade na medida em que se consolidada internamente as diferentes modalidades de ensino, ganhando experiência para implantação de cursos a distância.

\section{O DOCENTE E O ENSINO SEMIPRESENCIAL}

O ensino semipresencial exige o uso dos recursos tecnológicos de informação e de comunicação. Como dito nem todos os professores foram adequadamente preparados para atuar no ensino a distância por meio de tais instrumentos.

$\mathrm{Na}$ semipresencialidade o aprendente é mais autônomo já que a autoaprendizagem o educa pra isso. O docente, para esse novo aprendente, é mais um dos recusos para o processo formativo. $\mathrm{O}$ gestor do processo de ensino aprendizagem é o aluno. Evidentemente que esta aprendizagem autônoma é discutível e trata-se de uma questão complexa, sendo ainda, para muitos, apenas um ideal. Mas o caminho está aberto e a tendência é aumentar a autonomia do estudante no processo de construção do conhecimento (BELLONI, 2009).

Outros aspectos poderiam ser citados evidentemente, mas a partir da análise dessas duas realidades, já é possível discutir o papel do docente no ensino semipresencial.

Como dito amiúde, a maioria dos professores não foram formados para o ensino a distância. Muitos estão aprendendo a fazer educação a distância fazendo! Nem todos tem intimidade com os recursos hoje disponíveis. Esse fator é determinante porque com os recursos tecnológicos são criadas situações novas de aprendizagem. A organização didática precisa ser revista à luz das tecnologias da informação e da comunicação.

Formar o docente para atuar nos ambientes virtuais de aprendizagem (AVA), é essencial para o êxito no uso da semipresencialidade. Se o professor não for devidamente preparado para lidar com os recursos e se ele não aceitar que na educação a distância seu papel não será central corre-se o risco do insucesso. A exígua formação pedagógica em processos educacionais mediados 
pelas modernas tecnologias gera, na maioria das vezes, as desconfianças e resistências.

$\mathrm{Na}$ verdade a educação dita convencional sempre serviu-se de atividades não presenciais. As "tarefas de casa" eram mecanismos complementares de estudo e reforço. O aluno precisava se organizar para conciliar o tempo destinado às brincadeiras e o tempo para realizar as atividades determinadas para serem feitas em casa. O ensino semipresencial nada mais é do que o emprego dos recursos tecnológicos para realização de "tarefas" complementares. Com o auxilio das tecnologias interativas as atividades virtuais revisam e complementam os conteúdos discutidos de modo presencial. O que difere da educação convencional, é que por meio da interatividade virtual, o aluno sentirá a aproximação do professor na execução das "tarefas", o que no modelo convencional seria impossível. Essa compreensão pode estimular os docentes mais resistentes na busca de inovação, aceitação e capacitação para atuar por meio dos recursos técnicoeducacionais.

Portanto, ao desempenhar suas funções no ensino semipresencial o professor poderá se descobrir como "parceiro do estudante" (BELLONI, 2009). O que não significará perda e sim uma nova compreensão do seu papel como facilitador e mediador na construção do conhecimento. Ele aprenderá a ser ao mesmo tempo mestre e aprendiz.

O segundo aspecto escolhido, dentre outros, para abordar a relação entre docente e a semipresencialidade foi a centralidade do aluno.

O aluno é, diferentemente do passado, um "nativo digital", ele toma consciência de si em ambientes repletos de recursos tecnológicos e adquire habilidades, desde muito cedo, para lidar com tais recursos (CARLINI; TARCIA, 2010). Isso faz do aluno moderno um polivalente ao conseguir realizar inúmeras tarefas ao mesmo tempo.

O processo de socialização dos adolescentes está envolto pelos ambientes virtuais, o que significa que a educação a distância em geral, e semipresencial de modo particular, é natural para ele. Se não é natural não é, todavia, "coisa de outro mundo". A semipresencialidade pode até ser vista por esse aluno moderno como "facilidade" em um primeiro momento caso não tenha sido discutida as suas bases epistemológicas. Todavia, ele sente-se muito bem preparado para lidar com os recursos e aprender por mediação deles. Diferentemente de boa parte dos docentes.

Como já acenado, segundo Belloni o conceito de aprendente autônomo é ainda embrionário, mas deve ser encorajado (2009). A educação a distância e o ensino sempresencial contribuem para que isso aconteça. 
Desse modo existe um aluno preparado e conhecedor dos recursos tecnológicos e que aos poucos irá adquirindo autonomia na construção do conhecimento promovendo a qualidade de sua própria formação. Por meio da semipresencialidade ele pode ser estimulado a responsabilizar-se mais pela sua capacitação. O professor, nesse contexto, perderia sua posição privilegiada de detentor do conhecimento se colocando ao lado do estudante na condição de parceiro. O professor precisa ser preparado para essa transição.

As duas abordagens acima evidenciam que a relação entre o docente e o ensino semipresencial pode ser complexa quando o processo não é bem conduzido pelas Instituições de Ensino.

De qualquer modo o ensino presencial pode ser muito enriquecedor a médio e longo prazo. Superadas as dificuldades iniciais, vencidas as resistências, construídos e explanados os fundamentos epistemológicos a semipresencialidade pode contribuir positivamente no processo de ensino aprendizagem. Agora é evidente que o sucesso dessa modalidade depende da Instituição e do professor, muito mais do que do aluno.

\section{CONCLUSÃO}

A educação a distância desenvolveu-se a partir da evolução da tecnologia. Com o avanços dos recursos tecnológicos surgiram novas oportunidades na educação. Nos dias atuais, professores e alunos não necessitam mais estarem juntos no mesmo espaço físico para desenvolver o processo de ensino e aprendizagem.

A educação a distância, desde seu surgimento na forma de correspondência até os modernos ambientes virtuais de aprendizagem, tem contribuído para a formação e qualificação das pessoas.

Com a difusão dessas novas tecnologias e sua aplicação no ensino, a modalidade de educação a distância foi reconhecida e desde a LDB de 96 regulamentada.

Cabe às Instituições de Ensino Superior utilizar e pesquisar novos recursos tecnológicos com aplicação didático-pedagógica não convencionais, por meio de modalidade de ensino a distância, especialmente na formação de acadêmicos para a inclusão e manutenção dos mesmos nesta sociedade digital.

A abertura para novas aprendizagens tem sido considerada como uma das habilidades necessárias para o desenvolvimento pessoal e profissional em todos os momentos da vida. E, nesse contexto, a educação a distância surge como uma das possibilidades para o processo de formação inicial e continuada 
de profissionais que não têm a possibilidade de freqüentar o ensino presencial. Com o ensino virtual é possível direcionar futuras formações. A incorporação dos avanços tecnológicos à educação representa um caminho novo para o processo de aprendizagem.

A modalidade semipresencial, no contexto do ensino a distância, constitui um instrumental válido de complementação de estudos. Mas sua contribuição mais efetiva para o aluno pode estar no desenvolvimento de sua autonomia. As tendências mais fortes arriscam que a ação educativa será centrada no estudante e por meio de recursos tecnológicos de informação e comunicação.

Destarte, é urgente a criação da cultura online nos alunos, e, sobretudo, nos professores e principalmente nos cursos de graduação superior, para que haja o hábito de utilizar a internet fora da escola, como ferramenta de estudo e parte integrante dos cursos e do processo de aprender.

A implantação da semipresencialidade pode ser enriquecedora quando bem planejada. A sua inclusão deverá seguir fases bem elaboradas de planejamento e execução no sentido de ultrapassar as resistências e animosidades que possam surgir. No decorrer do texto foi visualizado a necessidade de redefinição do papel do professor, centralizando o foco na aprendizagem do aluno, sendo o professor o parceiro e mediador deste processo.

A questão fundamental da semipresencialidade está na lógica de complementar os conteúdos presenciais com o uso da tecnologia em ambientes virtuais, sendo que o êxito pedagógico dessa prática dependerá da Instituição e dos docentes que se propuserem a trabalhar com esta modalidade.

\section{REFERÊNCIAS}

BELLONI, Maria Luiza. Educação a distância. Campinas, SP: Autores Associados, 2009.

BRASIL.MINISTÉRIO DA EDUCAÇÃO. Teleducação no Brasil. Rio de Janeiro, [s.d.]

BRASIL. MINISTÉRIO DA EDUCAÇÃO. Lei de Diretrizes e Bases da

Educação. 1996. Disponível em: < http://www.planalto.gov.br/ccivil_03/leis/ L9394.htm>. Acesso em: 29 maio 2012.

BRASIL.MINISTÉRIO DA EDUCAÇÃO. Portaria no 4.059, de 10 de dezembro de 2004. 2004. Dispõe sobre as disciplinas semipresenciais em 
cursos superiores presenciais. Disponível em: $<$ http://portal.mec.gov.br/cne/ arquivos/pdf/2007/rces002_07.pdf >. Acesso em: 05 dez. 2011.

BRASIL.MINISTÉRIO DA EDUCAÇÃO. Resolução nº 2, de 18 de junho de 2007. 2007a. Dispõe sobre carga horária mínima e procedimentos relativos à integralização e duração dos cursos de graduação, bacharelados, na modalidade presencial. Disponível em: <http://portal.mec.gov.br/cne/ arquivos/pdf/2007/rces002_07.pdf>. Acesso em: 05 mar. 2012.

BRASIL.MINISTÉRIO DA EDUCAÇÃO. Resolução no 3, de 2 de julho de 2007. 2007b. Dispõe sobre procedimentos a serem adotados quanto ao conceito de hora-aula, e dá outras providências. Disponível em: $<\mathrm{http}: / /$ portal.mec.gov.br/cne/arquivos/pdf/rces003_07.pdf>. Acesso em: 28 nov. 2011.

CARLINI, Alda Luiza; TARCIA, Rita Maria Lino. 20\% a distância e agora? Orientações práticas para o uso de tecnologia de educação a distancia no ensino presencial. São Paulo: Pearson, 2010.

KENSKI, V. M. Tecnologias e ensino presencial e a distância. Campinas: Papirus, 2003.

MERCADO, Luis Paulo Leopoldo. Formação continuada de professores e novas tecnologias. Maceió: EDUFAL, 1999.

MORAN, J, M. Modelos e avaliação do ensino superior a distância no Brasil. Educação Temática Digital, Campinas, v. 10, n. 2, p. 54-70, jun. 2009. Disponível em: $<$ http://www.fae.unicamp.br/etd $>$. Acesso em: 15 nov. 2011.

PRETI, Oreste. Educação a distância: fundamentos e política. Cuiabá, MT: EdUFMT, 2011.

SACCO, Amarolinda; SCHLEMMER, Eliane; BARBOSA, Jorge.

M-learning e u-learning: novas perspectivas da aprendizagem móvel e ubíqua. São Paulo: Pearson, 2010.

SARAIVA, Terezinha. Educação a distância no Brasil: lições da história. Em Aberto, Brasília, v. 16, n.70, abr./jun. 1996.

TORI, Romero. Educação sem distância: as tecnologias interativas na redução de distâncias em ensino e aprendizagem. São Paulo: SENAC, 2010. 